Technological University Dublin

DƯBLIN

ARROW@TU Dublin

Articles

Crest: Centre for Research in Engineering

Surface Technology

2004

\title{
Microwave Induced Preparation of a-axis Oriented Double-Ended Needle-Shaped ZnO Microparticles
}

\author{
Suresh Pillai \\ Technological University Dublin, suresh.pillai@tudublin.ie \\ John Kelly
}

Graeme Watson

See next page for additional authors

Follow this and additional works at: https://arrow.tudublin.ie/cenresart

Part of the Materials Science and Engineering Commons

\begin{abstract}
Recommended Citation
This Article is brought to you for free and open access by the Crest: Centre for Research in Engineering Surface Technology at ARROW@TU Dublin. It has been accepted for inclusion in Articles by an authorized administrator of ARROW@TU Dublin. For more information, please contact arrow.admin@tudublin.ie, aisling.coyne@tudublin.ie,gerard.connolly@tudublin.ie.
\end{abstract}

Ledwith, D., Pillai, S. C., Watson, G., Kelly, John M. Microwave assisted synthesis of highly oriented ZnO needles, Chemical Communications, 2004, 2294-2295. doi:10.1039/B407768G

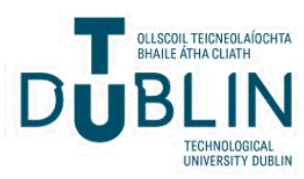




\section{Authors}

Suresh Pillai, John Kelly, Graeme Watson, and Deirdre Ledwith

This article is available at ARROW@TU Dublin: https://arrow.tudublin.ie/cenresart/26 


\title{
Microwave induced preparation of $a$-axis oriented double-ended needle-shaped $\mathrm{ZnO}$ microparticles $\dagger$
}

\author{
Deirdre Ledwith, Suresh C. Pillai, Graeme W. Watson and John M. Kelly* \\ Department of Chemistry, The University of Dublin, Trinity College, Dublin 2, Ireland. \\ E-mail: jmkelly@tcd.ie; Fax: 353-1-6712826; Tel: 353-1-6081947
}

Received (in Cambridge) 25th May 2004, Accepted 9th July 2004

First published as an Advance Article on the web 1st September 2004

Microwave irradiation of solutions of $\mathrm{Zn}\left(\mathrm{NO}_{3}\right)_{2}$ and urea provides a straightforward route to $a$-axis oriented crystals of needle-like morphology.

Hydrothermal methods are recognised as excellent procedures for the preparation of crystalline nano- and micro-particular metal oxides as the resulting particles have narrow size distribution, good crystallization, phase purity and comparatively few agglomerates. $^{1,2}$ As part of a programme to develop routes to $\mathrm{ZnO}$ nano- and micro-materials with optimal electronic and optical properties, ${ }^{2,3}$ we have recently studied the effect of microwave radiation on the reaction of aqueous solutions of $\mathrm{Zn}\left(\mathrm{NO}_{3}\right)_{2}$ and urea, as thermal reaction of urea in water solution is known ${ }^{4}$ to form $\mathrm{ZnO}$ via the overall reaction

$$
\mathrm{Zn}^{2+}+\mathrm{CO}\left(\mathrm{NH}_{2}\right)_{2}+2 \mathrm{H}_{2} \mathrm{O} \rightarrow \mathrm{ZnO}+\mathrm{CO}_{2}+2 \mathrm{NH}_{4}^{+}
$$

We report that not only does this microwave procedure yield $\mathrm{ZnO}$ microparticles much more rapidly than conventional heating methods, it also produces $\mathrm{ZnO}$ with a quite different well-defined needle-like morphology based on an unusual and unexpected $a$-axis orientation.

In a typical experiment $80 \mathrm{~cm}^{3}$ of $5 \times 10^{-3} \mathrm{M}$ zinc nitrate and $5 \times 10^{-2} \mathrm{M}$ urea were mixed in a Teflon ${ }^{\mathbb{B}}$ bomb and irradiated at $150 \mathrm{~W}$ for $20 \mathrm{~min}$. The pressure was then released and the sample allowed to cool to room temperature before filtering using a $0.45 \mu \mathrm{m}$ membrane filter. Powder X-ray diffraction (XRD) showed that the product was $\mathrm{ZnO}$ but with a strikingly different intensity pattern (Fig. 1a) than polycrystalline zincite $\mathrm{ZnO}$ (Fig. 1b). In particular the peak corresponding to $c$-axis orientation (002) is strongly diminished, while that corresponding to $a$-axis growth is dominant (Joint Committee on Powder Diffraction Standard (JCPDS) card number-36-1451). It may be noted that while a growing number of papers is concerned with $\mathrm{ZnO}$ having interesting morphologies (wires, rods and spindles etc.), the vast majority of samples until recently have been either $c$-axis oriented or randomly oriented. ${ }^{1-9}$ By contrast $a$-axis oriented samples are much less common, although there have been some reports of $a$-axis oriented thin films grown on (100) oriented substrates ${ }^{10-14}$ and the controlled growth by solid-vapour synthesis of (001) surface dominated $\mathrm{ZnO}$ nanobelts has recently been described. ${ }^{15}$ However to the best of our knowledge the present observation is the first report of a bulk chemical synthesis of $a$-axis oriented samples.

The product was further characterised by field emission scanning electron microscopy (FESEM), which revealed that the material consists of uniform double-ended needles $(11 \pm 2 \mu \mathrm{m}$ in length, with extremely sharp tips). Transmission electron microscopy (TEM) demonstrated that the tip is approximately $12 \mathrm{~nm}$ in diameter (Fig. 2c and d).

In order to define the conditions required to produce these unusual microparticles, we have carried out preliminary studies on the effect of time and power of the microwave irradiation,

$\dagger$ Electronic supplementary information (ESI) available: (1) Growth of $\mathrm{ZnO}$ needles; (2) effect of hot filtration; (3) effect of counterions. See http:// www.rsc.org/suppdata/cc/b4/b407768g/
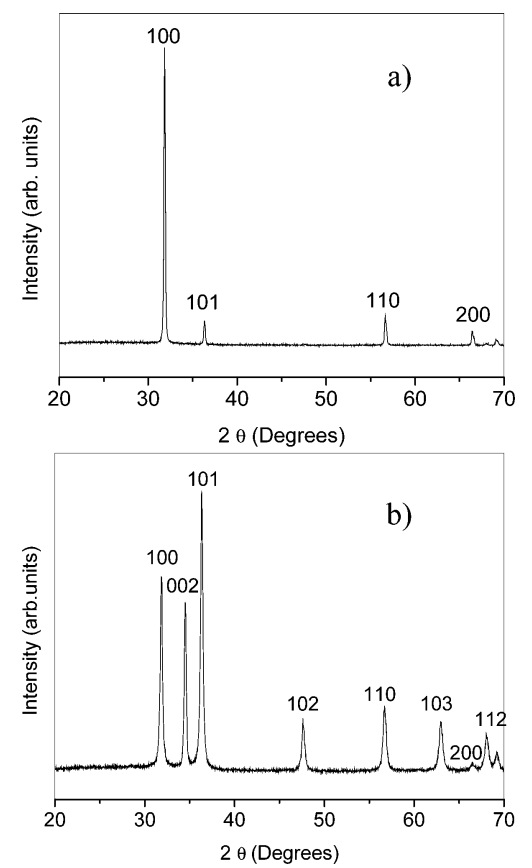

Fig. 1 XRD of (a) (100) oriented $\mathrm{ZnO}$ needles (b) $\mathrm{ZnO}$ sample (features corresponding to those of JCPDS card No. 36-1451).

concentration of zinc salt and the nature of the counterion. These indicate that the synthesis of the microparticles is very sensitive to the precise conditions used.

No particles are observed if the sample is irradiated for less than 15 min (i.e. until the temperature reaches $c a .90^{\circ} \mathrm{C}$ ). Some $\mathrm{ZnO}$ can be isolated (yield $=10 \%$ ) after 16 min microwave irradiation and subsequent cooling, but the XRD pattern (Fig. 3) shows random orientation (e.g. ratio of $100: 101$ reflections $=100: 56)$. After
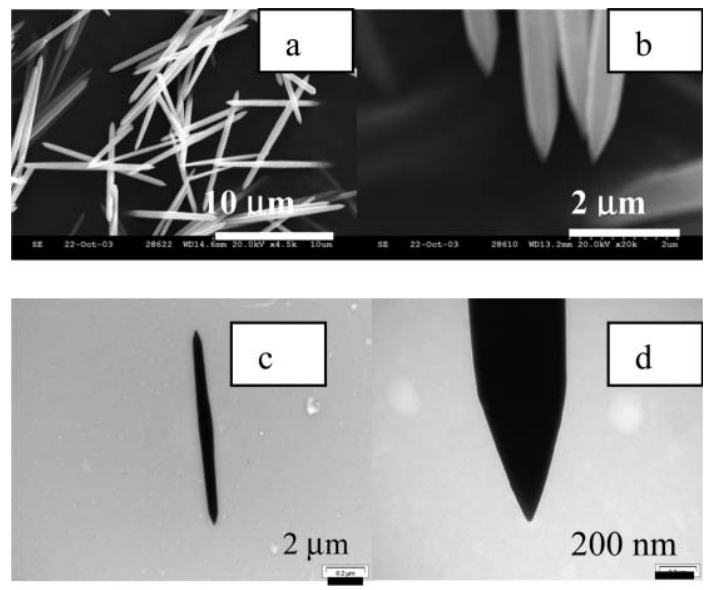

Fig. 2 FESEM of (a) $\mathrm{ZnO}$ needles, (b) needle tip; TEM of (c) single $\mathrm{ZnO}$, (d) tip of $\mathrm{ZnO}$ needle. 


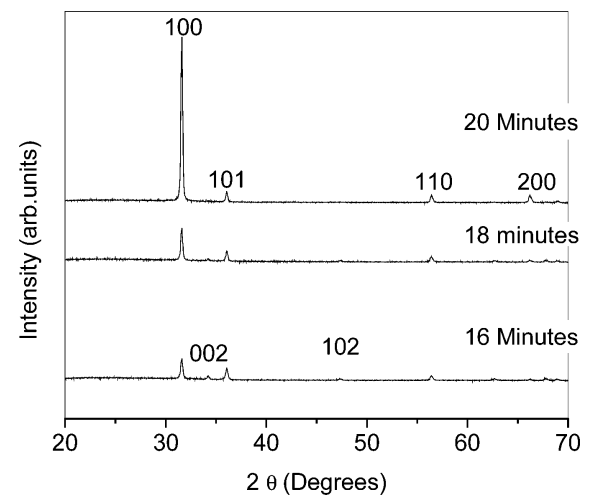

Fig. 3 XRD of $\mathrm{ZnO}$ material prepared by microwave irradiation of $5 \times$ $10^{-3} \mathrm{M}$ zinc nitrate and $5 \times 10^{-2} \mathrm{M}$ urea for between 16 and $20 \mathrm{~min}$.

$18 \mathrm{~min}$ this ratio has become $100: 30$ and it increases further to $c a$. $100: 7$ on irradiating for $20 \mathrm{~min}$. No further changes are noted on treating for longer periods. At this point peaks characteristic of $c$-axis growth, e.g. the (002) peak, have almost disappeared and that expected for $a$-axis orientation, (100), dominates. ${ }^{11}$ The FESEM studies show that after 16 min irradiation there are some (approximately 50\%) double-ended needles present but the tips are not well defined and most particles are poorly shaped [ESI (1)†]. As irradiation time increases the needles grow and the tips become sharper. Extending microwave heating beyond 20 min has no effect on the morphology of the $\mathrm{ZnO}$ needles, in agreement with the XRD results reported above.

In order to try to understand the growth mechanism, the conditions under which the reaction mixture was filtered were varied. When the sample was filtered hot (i.e. immediately after releasing the pressure following microwave irradiation), the XRD showed the presence of $a$-axis oriented particles. However, FESEM studies showed that the tips of the needles are not completely formed and the length of the needles were shorter $(9 \pm 2 \mu \mathrm{m})$ than the average length of the needle produced upon cooling to room temperature [ESI (2)†]. It is evident from these results that the nucleation is facilitated by microwave irradiation and that growth occurs in the solution during cooling to room temperature.

A change in zinc counterion also has a profound effect on the product [ESI (3)†], even when all other conditions were kept constant. Thus zinc acetate $\left(5 \times 10^{-3} \mathrm{M}\right)$ yielded irregular sized needles of randomly oriented crystalline $\mathrm{ZnO}$, while zinc sulfate $\left(5 \times 10^{-3} \mathrm{M}\right)$ gave a product which could not be identified by XRD.

It is striking that the external morphology of the $\mathrm{ZnO}$ produced by cooling after $20 \mathrm{~min}$ irradiation is similar to that reported by Wang et al.$^{16}$ for reaction of $\mathrm{Zn}(\mathrm{OH})_{2}$ in pure water or $1 \mathrm{M} \mathrm{KOH}$ at $200{ }^{\circ} \mathrm{C}$. They proposed that the growth occurred by the twinning of $\mathrm{ZnO}$ crystals and in their case the growth was clearly along the $c$-axis. By contrast our XRD results show that in the microwave reaction growth is along the $a$-axis. The formation of these microcrystals may be due to the creation of nuclei by the microwave radiation or possibly as a consequence of the sudden release of pressure after such treatment. These nuclei may be composed of zincite, but containing a high density of defects, as it is known from very recent studies ${ }^{, 11,17}$ that defects can strongly affect the surface free energy of the various planes, so that growth along the $c$-axis will no longer be preferred. Alternatively it is possible that the nuclei are composed of sphalerite, the much rarer cubic form of $\mathrm{ZnO}$, and that the growth of the zincite needles originates on the (100) face of this material. A role for the preferential adsorption of urea or some product derived therefrom is also likely.

In summary, a reproducible method for the synthesis of $a$-axis ordered, single crystal zinc oxide of an unusual morphology has been established. Double-ended needles of $11 \pm 2 \mu \mathrm{m}$ with extremely sharp tips $(12 \mathrm{~nm})$ have been prepared and characterized. Studies of the optical and electronic properties of the material are planned. One potential application for the needles is in the fabrication of AFM cantilevers, ${ }^{18}$ which requires micron-sized particles with sharp tips capable of probing surfaces.

The authors gratefully acknowledge the financial support of HEA (PRTLI Materials programme). We thank Dr Declan McCormack, Dr Yurii Gun'ko and Dr Michael Bridge for helpful discussions.

\section{Notes and references}

1 W. J. Dong, G. S. Pang, Z. Shi, Y. H. Xu, H. Y. Jin, R. Shi, J. J. Ma and S. H. Feng, Mater. Res. Bull., 2004, 39, 433.

2 R. A. McBride, J. M. Kelly and D. E. McCormack, J. Mater. Chem., 2003, 13, 1196.

3 S. C. Pillai, J. M. Kelly, D. E. McCormack, P. O'Brien and R. Ramesh, J. Mater. Chem., 2003, 13, 2586; S. C. Pillai, J. M. Kelly, D. E. McCormack and R. Ramesh, J. Mater. Chem., 2004, 14, 1572; S. C. Pillai, J. M. Kelly, D. E. McCormack and R. Ramesh, Mater. Sci. Tech., 2004, 20, 964.

4 E. Tsuchida and S. Kitajima, Chem. Lett., 1990, 1769.

5 D. S. Boyle, K. Govender and P. O'Brien, Chem. Commun., 2002, 80.

6 P. X. Gao, Y. Ding and Z. L. Wang, Nano Lett., 2003, 3, 1315.

7 M. H. Huang, Y. Wu, H. Feick, N. Tran, E. Weber and P. Yang, $A d v$. Mater., 2001, 13, 113 .

8 L. Vayssieres, K. Keis, S. E. Lindquist and A. Hagfeldt, J. Phys. Chem. $B, 2001,105,3350$.

9 R. Turgeman, O. Gershevitz, O. Palchik, M. Deutsch, B. M. Ocko, A. Gedanken and C. N. Sukenik, Cryst. Growth Des., 2004, 4, 169.

10 N. H. Tran, A. J. Hartmann and R. N. Lamb, J. Phys. Chem. B, 1999, $103,4264$.

11 J. Lu, Z. Ye, J. Huang, L. Wang and B. Zhao, Appl. Surf. Sci., 2003, 207, 295.

12 X-H. Wang, J. Shi, S. Dai and Y. Yang, Thin Solid Films, 2003, 429, 102.

13 N. Matsunami, M. Itoh, Y. Takai, M. Tazawa and M. Sataka, Nucl. Instrum. Methods Phys. Res., Sect. B, 2003, 206, 282.

14 B. J. Lokhande, P. S. Patil and M. D. Uplane, Mater. Lett., 2002, 57, 573.

15 X. Y. Kong and Z. L. Wang, Nano Lett., 2003, 3, 1625.

16 B. G. Wang, E. W. Shi and W. Z Zhong, Cryst. Res. Technol., 1998, 33, 937.

17 B. G. Wang, Z. P. Lu, E. W. Shi and W. Z. Zhong, Cryst. Res. Technol., 1998, 33, 929.

18 W. L. Hughes and Z. L. Wang, Appl. Phys. Lett., 2003, 82, 2886. 